\title{
Vegetation Database of the Cilento National Park
}

\author{
Leonardo Rosati, Eva Del Vico, Laura Facioni \& Mattia Martin Azzella
}

\begin{abstract}
A TURBOVEG database, including both original and published phytosociological relevès from the Cilento and Vallo di Diano National Park (Southern Italy), was compiled to support environmental monitoring, landscape planning and vegetation classification. Approximately 2,300 relevès were stored in the database including all the natural and semi-natural vegetation types, ranging from sand dunes (Cakiletea maritimae) to dwarf shrub subalpine vegetation (Pino-Juniperetea). Data span from 1970 to nowadays, updated with the most recent research project. We considered for inclusion in the database phytosociological relevés or any other vegetation plots containing records of species composition (of at least vascular plants) and an estimate of species cover. We extended the standard structure of the database by adding extra fields to fit particular needs, such as including the accuracy of the data location (i.e. a crucial issue for environmental monitoring). A reference check-list of the taxa was set up mostly following Conti et al. (2005) including several largely adopted synonymous to facilitate the correct input of relevé data. Ecological databases are linked to the vascular species using Ellenberg indicator values and including life forms or chorotypes. The database contains useful information to test several ecological hypotheses and to perform wide-scale vegetation classifications. Furthermore it facilitates the use of vegetation-plot data for biodiversity and habitat monitoring and also for land use/cover changes evaluation. This report describes the available content in the Vegetation Database of the Cilento National Park (GIVD ID EU-IT-002).
\end{abstract}

Keywords: nature conservation; phytosociology; vegetation classification.

GIVD Database ID: EU-IT-002

Last update: 2012-07-09

\section{Vegetation Database of the Cilento National Park}

Scope: To classify and monitor the vegetation of Cilento and Vallo di Diano National Park (Southern Italy) including the buffer zone (approx. 3000 km2), all available phytosociological relevés original and published, were compiled and stored in a TURBOVEG Database.

Status: completed and continuing

Period: 1970-201

Database manager(s): Leonardo Rosati (leonardo.rosati@unibas.it)

Owner: Leonardo Rosati (private)

Web address: [NA]

Availability: according to a specific agreement

Database format(s): TURBOVEG

Publication: [NA]

Plot type(s): normal plots

Non-overlapping plots: 2,289

Total plot observations: 2,289

Online upload: $n$

Online search: no

Export format(s): TURBOVEG, MS Access, Excel, CSV file

Countries: IT: $100.0 \%$

Forest: [NA] - Non-forest: [NA]

Guilds: all vascular plants: $100 \%$

Environmental data: altitude: $88 \%$; slope aspect: $90 \%$; slope inclination: $78 \%$; soil depth: $84 \%$; other soil attributes: $21 \%$

Performance measure(s): cover: $100 \%$; measurements like diameter or height of trees: $21 \%$

Geographic localisation: GPS coordinates (precision $25 \mathrm{~m}$ or less): $46 \%$; point coordinates less precise than GPS, up to $1 \mathrm{~km}$ : $35 \%$; small grid (not coarser than $10 \mathrm{~km}): 19 \%$; political units or only on a coarser scale $(>10 \mathrm{~km}): 10 \%$

Sampling periods: [NA]

Information as of 2012-07-12; further details and future updates available from http://www.givd.info/ID/EU-IT-002

Leonardo Rosati* (leonardo.rosati@unibas.it)

Biology, Università della Basilicata, Via dell'Ateneo Lucano 10, 85100 Potenza, ITALY

Laura Facioni (laura.facioni@gmail.com), Eva Del Vico (evadelvico@gmail.com), Mattia Martin Azzella (mattia.azzella@gmail.com) Department of Environmental Biology, Sapienza University of Rome, P.le Aldo Moro 5, 00185 Rome, ITALY

*Corresponding author 